\title{
ECONOMETRIC MODELLING OF INDICATORS OF INNOVATION ACTIVITY LEVEL
}

\author{
Natalia Grigoryeva and Rezeda Kundukchyan \\ Institute of Management and Territorial Development, Kazan (Volga Region) Federal University, Kazan, Russia
}

Received 2014-04-01; Revised 2014-07-30; Accepted 2014-08-05

\begin{abstract}
In the article we attempt to identify indicators that have a significant impact on the level of innovation activity, for a deeper understanding of the essence and principles of the innovative process. This article presents the econometric analysis. The model of multiple regression was built. Econometric modeling was carried out based on statistical data on regions of Russia. The study proved the high importance of organizational innovations and investments for increase of innovative activity of economic entities.
\end{abstract}

Keywords: Econometrics, Modelling, Innovation, Innovative Process, Economic Growth, Regional Economy

\section{INTRODUCTION}

According to recent studies, the level of innovation activity depends on the level of development, which was achieved by regions and separate enterprises. Formation of modern structures that would be innovation-oriented depends on different combinations of factors of internal and external environment (Baranenko et al., 2014). Managing by innovation regions and enterprises involves the use another methods-for example, scenario technologies like foresight-designing and roadmapping (Baranenko et al., 2014). Iterative and interactive models have replaced the traditional linear model of innovation during the last decade. Innovation is about creating meaning; that it is inherently social; and is grounded in existing social practices (Tuomi, 2014). Innovative projects, as a rule, have high risks, although potentially may lead to significant direct and indirect (for example, social or environmental effects) benefits (Jeston and Neilis, 2013). As a rule, the creation of numerous innovative projects in the region leads to growth of incomes of the population, to improve the quality of copyright protection. Also it leads to improve the connection between education and business (Gromov, 2014). The increasing complexity of business and social settings has lead to innovation becoming strategic imperative.
The structure of expenditure on innovations is different in different firms. So, according to the report, which was published by (EC, 2013), industry sector companies are most likely to have directed more than 5\% of their investment in training (25\%) and company reputation and branding $(28 \%)$ in innovation projects (EC, 2013). Service sector companies are most likely to have directed more than $5 \%$ of their investment in $\mathrm{R}$ and D $(28 \%)$ to innovation project (EC, 2013). Also companies spent their investment in organization or business process improvements or product or service design towards innovation projects.

It is generally accepted that innovation may not be distributed evenly in various reasons. According to the Regional Innovation Scoreboard 2014 (EC, 2014) all the Europe Union (EU) regional innovation leaders (27 regions) are located in only eight EU Member States: Denmark, Germany, Finland, France, Ireland, Netherlands, Sweden and United Kingdom. This indicates that innovation excellence is concentrated in relatively few areas in Europe.

For deeper understanding of the innovation process, we attempt to identify the indicators that have a significant impact on the level of innovation activity.

With the acceleration of scientific and technological progress, an important factor in the dynamics of socioeconomic development is the speed of improvement and creation of new products, services and technologies with

Corresponding Author: Natalia Grigoryeva, Institute of Management and Territorial Development,

$$
\text { Kazan (Volga Region) Federal University, Kazan, Russia }
$$


increasing the intensity of innovative activity. The urgency of stimulating innovative activity caused by the low share of innovative products in the structure of the products, manufactured on the territory of Russia and the predominance of raw materials orientation of the existing facilities, the presence of a number of inefficient industries with low productivity, as well as the need to improve competitiveness in the global market to achieve sustainable development.

At the same time, we need a corresponding institutional framework which encourages innovation activity. Some researchers believe that for the implementation, for instance, the cluster policy, the level of innovative development of regions should not be below average. And these conditions are true only for a few regions of Russia (Zhiltsova, 2012).

\section{MATERIALS AND METHODS}

One of the important directions in the study of innovation is using modeling tools, which allow identifying factors that determine the development of private economic processes. In practice, innovation often is a random variable. However, given the General trend to increase of innovative activity, the number of innovation projects increases and becomes a regular phenomenon. In reality, the cumulative behavior of a relatively large number of random variables almost loses a random character and acquires certain regularities.

Process simulation enables to identify the main factors influencing the target. If you know the quantitative relationships between these factors and simulated indicator, you can improve the quality of management value target by the direct impact on its determinants. Knowing the extent and character of influence of each factor, it is possible to choose the most effective way to manage.

Using modeling tools improves the quality of planning. This is especially important in connection with the low effectiveness of the prepared forecasts of results of innovation and scientific activities.

In the course of our research we made the information base of statistical data on the following indicators: (1) Number of employees engaged in research; (2) the volume of innovative products, works and services; (3) payments to other countries for the import of technology; (4) the payments for the export of technologies to other countries; (5) expenses of the organizations in the region on technological innovation; (6) index of education in the region; (7) the share of innovative goods, works and services; (8) number of innovative technologies; (9) number of developed innovative technologies; (10) the flow of foreign investments on the entities. The information base of statistical data contained these indicators by administrative districts (regions) of Russia.

By a set of indicators was built the correlation matrix. The correlation coefficient is used to determine the relationship between two variables.

The education index is calculated by the author's method (Ekimova, 2009) which was carried out with the financial support of Russian Foundation for basic research. Educational potential of the regions was assessed in terms of the following indicators: Availability of educational services (the number of University students in the region per 10,000 population); financial security (the ratio of average monthly nominal accrued wages in the Education sector in the region and the living wage of the able-bodied population in the region); scientific productivity (the number of post-graduate students per 100,000 population) (Ekimova, 2009).

As a result of the analysis of statistical indicators we hypothesized that one of the major factors, which can evaluate innovativeness of regional economic system is the number of developed innovative technologies for a certain period (year).

This tool does not claim universal evaluation of the innovativeness of region, but it is easily applicable for the purposes of obtaining a general idea on the growth of innovative industry or innovative region for a certain period of time.

The main purpose of econometric modeling is to describe specific quantitative relationships caused by common qualitative regularities in the economic theory (Klimenko, 2011). The construction of the model in this research is aimed to the detection, analysis of statistical regularities in the economy and confirmation or refuting the primary hypothesis. To achieve this aim we have constructed a multiple regression model. Multiple regression model solves the problem of the dependence of one variable $(\mathrm{Y})$ of two or more explanatory variables $\left(X_{1}, X_{2}, \ldots, X_{\mathrm{n}}\right)$. The general equation of the model is represented by the formula 1 :

$$
Y_{i}=f\left(\mathrm{X}_{\mathrm{i} 1}, \mathrm{X}_{\mathrm{i} 2}, \ldots, \mathrm{X}_{\mathrm{in}}\right)
$$

The main goal of the multiple regression is to build a model with a large number of factors which identify the impact of each of them individually, as well as the cumulative effect of all factors on simulated indicator. The calculations were performed with the mathematical functions of MS Excel.

\section{RESULTS}

As the dependent variable (Y) was selected indicator: The number of generated innovative technologies (as a 
factor of innovation performance). As explanatory variables $\left(X_{1}-X_{5}\right)$ was selected: Expenses of the organizations of the region on technological innovations (the natural logarithm $(\ln )$ the amount of expenses- $\left.\ln X_{1}\right)$; the share of innovative goods, works and services $\left(X_{2}\right)$; the index of education in the region $\left(X_{3}\right)$; the volume of foreign investments (the natural logarithm $(\mathrm{ln})$ of volume of investments- $\ln X_{4}$ ); number of innovative technologies $\left(X_{5}\right)$. Since most of the factors in the model is of a relative nature of the data, the volume of foreign investments and expenditures organizations of the region on technological innovations have been restated in the form of natural logarithms, which allows more properly to take into account the dynamics of their changes among regions on a background of other factors. This is a common practice of research of financial indicators.

The sample was made according to statistics of 32 regions, covering Volga region Federal District (VFD), Siberian Federal District (SFD) and the Urals Federal District (UFD). Selected Federal districts occupy a similar proportion to its contribution to the GDP and have a similar structure of the economy. Central Federal district and Northwest Federal district were not included in the sample, because of availability of Federal cities (Moscow and St. Petersburg), which were significantly different from the average values of indicators. Using this data usually reduce the information content of calculation models.

The most recent period for which it is possible to obtain official statistical data about all studied indicators is 2010. Calculations were based on empirical data by regions of VFD, the SFD and UFD for one year, which were divided into two parts: According to the regions of VFD and the SFD model actually was built and according to the data of UFD-model was tested to ensure the verification of the model and the results of calculations.

The function of the linear multiple regression model on the basis of empirical data by regions of Volga Federal district and the Siberian Federal district presented by the formula 2 :

$$
\begin{aligned}
& Y=-13.01+0.4 * \text { in } X_{1}+0.13 * \\
& X_{2}+0.11 * X_{3}+0.43 * \operatorname{In} X_{4}+0.02 * X_{5}
\end{aligned}
$$

According to the model factors $x_{1}$ and $x_{4}$ have the greatest influence on the number of newly-created advanced technologies: The natural logarithm of costs organizations in the region on technological innovation and the volume of foreign investments.

Since the correlation between all indicators of the model does not exceed $70 \%$, we can assume that the problem of multicollinearity is missing.
It is important to note that the growth of investments does not itself provide improving climate for innovation, because these even was a negative correlation with the specific indicator of the weight of the innovative goods, works and services-the correlation coefficient is equal to0,143 . The leading role have projects that attract these investments. Economic clusters may be the center of attraction of investment resources in the economy of the region, providing the basis for long-term production, innovative and infrastructure projects.

The coefficient of determination $\left(R_{2}=0.62\right)$ is to test the goodness of fit of the model. Its value indicates a fairly high quality of the model.

Fisher's exact test is a statistical significance test used in the analysis of categorical data where sample sizes are small. Its value also confirms the quality of the model and the importance included in the calculations of the variables $X_{1}-X_{5}(\mathrm{p}<0.05)$.

So, $F$ estimated model is 9.13 -which is more than F critical (found on the Fisher's tables) 2.71. In conclusion, we reject the null hypothesis about the insignificancy of factors with risk of mistakes no more than 5\%. So, we can assume that the model is adequate statistical data and suitable for carry out economic analysis and forecasting $(\mathrm{p}<0.05)$.

Checking the quality of models on Student's Test, the coefficient $\mathrm{t}$, calculated on the tables of the t-test was 2.08. According to the Student's Test, the only significant factor in the model is the number of used technologies $\left(X_{5}\right)$, because only in relation to this factor condition t estimated is more than $\mathrm{t}$ critical. But Fisher's exact test, which is more accurate, confirms the importance of factors. The Durbin-Watson statistic (DW) for independence residues (autocorrelation) also confirms the absence of autocorrelation). $\mathrm{DW}=2.12$ and consequently falls within the interval $(1.5 ; 2.5)$, that testifies to absence of autocorrelation of the residuals and quality of model.

To avoid heteroskedasticity in the model, some of the variables in the model have been replaced with their logarithms.

Partly the discrepancy between the results of Student's Test and other can be explained by the non-linearity of the dependencies between these economic variables.

The public nature of economic relations is not $95 \%$ exactness mathematically describes the relationship between the number of created innovative technologies and other factors (according to Student's Test all factors become significant only at 35\% probability when $\mathrm{t}=0.39)$. Since innovation is nonlinear and dynamic process, there will always be flaws applied methodologies identification of innovations, the registration of the results of innovation and intellectual activities, bureaucratic 
procedures and reporting's mistakes. So, the achieved quality of the model can be regarded as satisfactory.

On the basis of the model (2) results for the test data set were calculated. Table 1 and 2 show the values of deviations about the number of developed innovative technologies in the regions $e_{i}$ (which were calculated by the formula (3)):

$e_{i}=Y_{\text {fact }}-Y_{\text {estimated }}$

Where:

$Y_{\text {fact }}=$ He actual value of the indicator according to the statistics

$Y_{\text {estimated }}=$ The estimated value of indicator according to model

Data from Table 1 and 2 shows that the actual number of developed advanced technologies are higher than the corresponding values calculated by the model $\left(e_{i}>0\right)$, in regions which are the investment centers. For example, there are centers of all Federal districts (Nizhny Novgorod region, Novosibirsk region, Sverdlovsk region) or regions which are actively implement the policy for the creation of economic clusters: Chelyabinsk region (pharmaceutical cluster, the cluster drives, «solar cluster», the cluster of mechanical engineering and Metalworking), Orenburg region (tourist, machine-building clusters), Perm region, Samara region, Saratov region.

The exception is the Tomsk region, where also actively implements the cluster policy: Pharmaceutical cluster, the cluster «Information technologies», «Solid-state microwave electronics», «Fluoride technologies», «West-Siberian atomic-industrial Alliance», forest cluster.

Also, the deviations confirms show that the creation and implementation of innovations is nonlinear process. So, in the Kirov region, Mari El Republic, Zabaikalsky Krai, Tyva Republic and Khakassia Republic the actual value of the number of developed advanced technologies for 2010 is zero, according to the Federal Service of State statistics (FSGS). Although expenditure on technological innovation is achieved. In most of these regions, the number of advanced technologies also less than the average value in the sample. This indirectly confirms the fact of the dependence of region's innovative potential (which is understood as the ability to create technology that qualify as advanced) from the reached level of technological and innovative development (which is characterized by a weight of innovative products and the number of used technologies) and indicates the positive influence of the developed environment of innovation activities in the regional economic systems to the number of generated innovation.
Table 1. The value of deviations in the number of developed innovative technologies (regions of the UFD)

\begin{tabular}{lr}
\hline Regions of & $\begin{array}{c}\text { The value of } \\
\text { deviations }\left(\mathrm{e}_{\mathrm{i}}\right)\end{array}$ \\
the UFD & -2 \\
\hline Kurgan region & 22 \\
Sverdlovsk region & -10 \\
Tyumen region & -5 \\
Khanty-Mansiysk Autonomous Okrug & -3 \\
Yamalo-Nenets Autonomous Okrug & 23 \\
Chelyabinsk region & 0 \\
\hline Altai Krai &
\end{tabular}

Source: Calculated by authors

Table 2. The value of deviations in the number of developed innovative technologies (regions of the VFD and SFD)

\begin{tabular}{lr}
\hline Regions of & $\begin{array}{c}\text { The value of } \\
\text { deviations }\left(\mathrm{e}_{\mathrm{i}}\right)\end{array}$ \\
the VFD & -5 \\
\hline Kirov region & 5 \\
Nizhny Novgorod region & 1 \\
Orenburg region & 0 \\
Penza region & 1 \\
Perm region & -10 \\
Bashkortostan republic & 0 \\
Mari El republic & -1 \\
Mordovia republic & 3 \\
Tatarstan republic & 2 \\
Samara region & 2 \\
Saratov region & -8 \\
Udmurt republic & -1 \\
Ulyanovsk region & 0 \\
Chuvash republic & \\
Regions of the SFD & -3 \\
Zabaikalsky Krai & 5 \\
Irkutsk region & 2 \\
Kemerovo region & -1 \\
Krasnoyarsk region & 14 \\
Novosibirsk region & -8 \\
Omsk region & 3 \\
Altai republic & 3 \\
Buryatia republic & 1 \\
Tuva republic & -1 \\
Khakassia republic & -4 \\
Tomsk region & \\
\hline Source: Calculated & \\
\hline
\end{tabular}

Source: Calculated by authors

\section{DISCUSSION}

However, when analyzing predictions by this model, it is necessary to consider the high uncertainty of the progress of scientific and technological progress and strong dependence of efficiency of innovation development of the socio-economic environment in the region, its ability to implement innovative development. Level of the human capital increases the speed of implementation new technologies. In a study (Safdari et al., 2010) noted that human capital in 
developed countries influences positively on economic growth through domestic innovation component.

So, as the development of qualitative and quantitative representations about the content of the innovation process and quantitative relations between its elements, mathematical models of socio-economic phenomena subject to adjustment.

However, the modeling process is a necessary tool which application allows to reveal and evaluate the quantitative factors influencing the learning process. It plays an important role for understanding the structure of the process of innovation development within a particular economic system. Also it important to determine the most effective mechanisms of innovation policy.

Thus, in the survey, conclusions can be drawn. The first, the number of created advanced technologies of $62 \%$ is explained by the values of the cost organizations in the region on technological innovations $\left(\mathrm{X}_{1}\right)$; specific gravity of innovative goods, works and services $\left(\ln \mathrm{X}_{2}\right)$; the index of education in the region $\left(\mathrm{X}_{3}\right)$; the amount of foreign investment $\left(\ln \mathrm{X}_{4}\right)$ and a number of innovative technologies $\left(\mathrm{X}_{5}\right)$. So, detected and mathematically proved a number of quantitative factors that have a significant impact on the number of created innovative technologies in the regional economy.

The sec. it is revealed that the increase in all described quantitative indicators $\left(\mathrm{X}_{1}-\mathrm{X}_{5}\right)$ entails a positive effect on the increase the number of created advanced technologies, but has a low elasticity. A greater effect on the level of innovativeness of the regional economic system have expenses of the organizations of the region on technological innovations and the volume of foreign investment.

The third, it is shown that the growth of investment by itself does not provide (not sufficient) to improve the climate for innovation.

The fourth, built an econometric model of multiple regression has high quality and suitable for economic modeling and forecasting. The quality of the model is confirmed by the Durbin-Watson statistic, Student's Test, Fisher's exact test, also we held a procedure of verification of forecast on the test data group. Accounted in the model factors objectively reflect the real economic processes and allow to assess the likely value of the number of newly created technologies, with a given initial parameters.

\section{CONCLUSION}

In conclusion, analysis of derivations showed that the actual number of developed innovative technologies above the calculated values in those regions which are the investment centers or actively implement the policy for the creation of economic clusters. Therefore, organizational innovations are important for increasing the innovativeness of the regional economic systems. This innovation allows to improve the innovation climate, create favorable conditions for attracting investments. According to the results of modeling, investments have the greatest impact on the resulting indicators of innovation (innovation costs can be considered as domestic investment in productive activities).

To sum up, we can talk about the importance of the system organization of innovative activities and the General environment, which is encourage to create and implement innovations. In this viewpoint it is expedient to speak about the innovation climate as the whole complex of the institutional environment for innovative activity and information space and the character of relations between all participants of the technological chain of production and commercialization of innovations.

\section{ACKNOWLEDGMENT}

The researchers thank Prof. Dr. Nailya G. Bagautdinova for the valuable discussions during the development of this study.

\section{REFERENCES}

Baranenko, S.P., M.N. Dudin, N.V. Ljasnikov and K.D. Busygin, 2014. Use of environmental approach to innovation-oriented development of industrial enterprises. Am. J. Applied Sci., 11: 189-194. DOI: 0.3844/ajassp.2014.189.194

Ekimova, N., 2009. The Capital of the Country. 1st Edn., Russian.

Gromov, G., 2014. Silicon Valley: History and future.

EC, 2013. Investing in intangibles: Economic assets and innovation drivers for growth. European Commission.

Jeston, J. and J. Neilis, 2013. Process innovation. Date Views.

Klimenko, T.I., 2011. The Formation of a management system for sustainable balanced development of clusters in the region: On the example of Tatarstan Republic. PhD Thesis, Kazan, Russia.

EC, 2014. Regional Innovation. Regional Innovation Scoreboard. Date Views.

Safdari, M., M. Shahiki and Z. Sheidaee, 2010. How does human capital affect on growth in different econ. J. Soc. Sci., 6: 416-423.

Tuomi, I., 2014. Networks of innovation: Change and meaning in the age of the internet.

Zhiltsova, U.V., 2012. The management of the innovation-oriented development in conditions of regionalization factors of sustained economic dynamics. PhD Thesis, Kazan, Russia. 